\title{
Length-mass relationships of Australian aquatic invertebrates
}

Vladimíra Dekanová ${ }^{\mathrm{B}, \mathrm{A}, \mathrm{D}}$

Michael Patrick Venarsky ${ }^{\mathrm{C}, \mathrm{A}}$

Stuart Edward Bunn ${ }^{\mathrm{A}}$

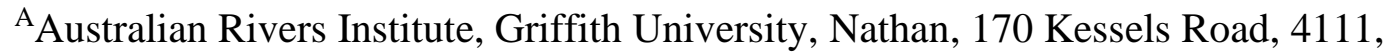
Queensland, Australia

${ }^{\mathrm{D} C o r r e s p o n d i n g ~ a u t h o r . ~ P o s t a l ~ a d d r e s s: ~ T e c h n i c a l ~ U n i v e r s i t y ~ i n ~ Z v o l e n, ~ D e p a r t m e n t ~ B i o l o g y ~}$ and General Ecology, 2117/24 T. G. Masaryka, 96001 Zvolen, Slovakia. Email: dekanovav@gmail.com. Telephone number: +421948 332800

\section{Acknowledgements}

This research was supported by the Australian Rivers Institute and Griffith University. We are grateful to Jacqueline Anderson for assistance with sample collection and taxa identifications.

${ }^{B}$ Department of Biology and General Ecology, Technical University in Zvolen, 2117/24 T. G. Masaryka, 96001 Zvolen, Slovakia

${ }^{\mathrm{C}}$ Department of Biodiversity Conservation and Attractions, Government of Western Australia, 17 Dick Perry Avenue, Kensington, Western Australia, 6151, Australia 


\title{
Length-mass relationships of Australian aquatic invertebrates
}

\begin{abstract}
Length-mass relationships for macroinvertebrates are used in many ecological studies, however, few length-mass relationships are available for Australian freshwater macroinvertebrates. In this study, we generated 22 new length-mass relationships from 2,148 specimens spread across four orders, nine families, three subfamilies, twelve genera, and two species. We also qualitatively compare our length-mass equations with others from Australia, New Zealand, North America, and Europe.
\end{abstract}

\section{Keywords}

length-mass relationship, body length, body weight, aquatic macroinvertebrate, Australia

\section{Introduction}

Length-mass relationships are widely used to estimate invertebrate biomass (Benke et al. 1999; Johnston \& Cunjak 1999; González et al. 2002). Length-mass relationships have advantages over other methods, such as direct weighing and biovolume methods, as the length-mass approach can be used on invertebrates of all sizes, does not destroy specimens, is relatively insensitive to sample preservation methods (ethanol, formalin, freezing), and provides biomass estimates for damaged specimens (Towers et al. 1994; Burgherr \& Meyer 1997; Johnston \& Cunjak 1999). However, macroinvertebrates are a diverse group of organisms with a variety of body shapes and sizes, meaning that length-mass relationships can exhibit substantial variation among different families or genera in the same order as well as among spatially separated populations of the same taxon group (Johnston \& Cunjak 1999). Thus, it is recommended that studies either use/develop length- mass relationships for the 
taxa of interest or select generalised (order, family, genus) length-mass relationships that were developed from locations in close geographic proximity to study sites (Gowing \& Recher 1985).

To date, we are aware of only two studies that have reported length-mass relationships for Australian freshwater macroinvertebrates (Pidgeon 1978; Marchant \& Grant 2015), with several other studies reporting either body-length or body-mass estimates for Australian aquatic insects (Edgar 1990; McKie et al. 2004; Hassell et al. 2006). In this study, we: (i) present 22 new length-mass relationships for various groups of Australian freshwater macroinvertebrates and (ii) qualitatively compare these new relationships to similar taxa in Australia, New Zealand, Europe and North America to explore variation in freshwater invertebrate length-mass relationships.

\section{Methods}

Study area

Freshwater invertebrates were collected from two sites in Queensland, Australia: Cedar Creek (sub-tropical southeastern Queensland: -2753’42.26", 153¹0’57.99") and

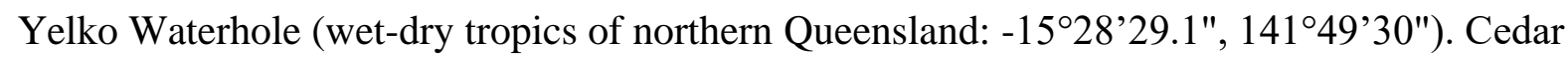
Creek was sampled five times between May and September 2018 and Yelko Waterhole was sampled once in June 2018.

\section{Specimen collection and processing}

We collected invertebrates from riffles, pools and macrophytes using a 500- $\mu \mathrm{m}$ dip net and then preserved specimens in 5\% formalin. We chose formalin preservation over ethanol preservation because ethanol dissolves lipids and can, thereby, reduce biomass estimates (Benke \& Huryn 2007; Mährlein et al. 2016). For freshwater macroinvertebrates, storage in 
preservative can lead to the leaching of body fluids and a loss of body mass (Leuven et al. 1985). We minimised this potential issue by processing all specimens within approximately one month of collection. We identified specimens to the lowest practical taxonomic level (usually genus) using the following keys: Suter et al. (2002), Theischinger and Hawking (2003), and online key Hawking et al. (2006).

We selected the least damaged specimens (i.e. fewest missing legs) and measured body length $( \pm 0.5 \mathrm{~mm})$ using a dissecting microscope with $1 \mathrm{~mm}$ graph paper fitted to the stage. We measured body length from the anterior end of the head capsule to the posterior end of the last abdominal segment, excluding anal prolegs and cerci. Curved individuals were straightened with forceps. We obtained measures of dry mass (mg) as follows: transferred individuals into pre-weighed and pre-combusted aluminium pans, oven-dried specimens at $60^{\circ} \mathrm{C}$ for $24 \mathrm{~h}$, cooled specimens in a desiccator for $12 \mathrm{~h}$, and then re-weighed specimens. We conducted all weighing on a micro-balance $( \pm 0.1 \mathrm{mg})$. Some specimens were too small to weigh individually, thus we pooled multiple individuals of the same size class into a single pan and divided the dry weight by the number of individuals in the pan to acquire average individual weights. In cases where genus- or species-level identification was not possible, individuals were grouped at the family level. We developed length-mass relationships for taxonomic groups when 10 or more individuals were collected and weighed. Dry mass was modelled as a function of body length using a power equation $\left(\mathrm{DM}=a \mathrm{BL}^{b}\right)$ and a natural $\log$-linear equation $(\ln \mathrm{DM}=\ln a+b \ln \mathrm{BL})$, where $\mathrm{DM}$ is dry body mass (mg), BL is body length (mm) and $a, b$ are constants (Johnston \& Cunjak 1999). We used the $1 \mathrm{~m}$ and nls functions in Program R (R Core Team 2020) to calculate constants for the linear and power equations, respectively.

We plotted body length (mm) versus dry mass (mg) and compared our power model with published models from Australia in Marchant and Grant (2015), North America (Benke 
et al. 1999), Europe (Baumgärtner \& Rothhaupt 2003) and New Zealand (Towers et al. 1994). In the published studies, we transformed linear models to power models when necessary.

\section{Results and Discussion}

Our literature review revealed only two other studies that reported length-mass relationships for Australian freshwater invertebrates. Pidgeon (1978) contained 38 body length-mass relationships from nine groups of insects, but samples sizes were small and body-size range was not included, suggesting that these relationships are not reliable. In contrast, Marchant and Grant (2015) published three relationships for Ephemeroptera based on body length and three relationships for Trichoptera based on head width. The relationships presented in Marchant and Grant (2015) were generated using large numbers of individuals from a range of body sizes, indicating that the equations from this study are reliable. In this study, we generated 22 new length-mass relationships for Australian freshwater macroinvertebrates from 2148 specimens spread across four orders, nine families, three subfamilies, 12 genera and two species (Table 1). Thus, our study represents a substantial, albeit limited, expansion of length-mass relationships for freshwater macroinvertebrates in Australia.

For most taxa, the natural-log transformed linear model resulted in either a higher or similar (i.e. $+3 \%$ ) coefficient of determination $\left(R^{2}\right)$ when compared with the power model. However, H. brevistylus (Odonata) was an exception as the power model had a much higher $R^{2}$ value than the linear model. The number of individuals per size class ( $1 \mathrm{~mm}$ size classes) was relatively evenly distributed for most taxa, but for Odonata most individuals were smallto medium-sized with a smaller number of very large, late instar individuals included in each model. Thus, we suspect the size distribution of taxa included in the models caused some 
power models to better predict length-mass relationships than the natural loglinear models and vice versa.

While we do not statistically compare length-mass relationships among studies, a qualitative comparison provides perspective on how the length-mass relationships of Australian taxa vary among regions (Figure 1; see Appendix S1: Table S1 for power model parameters). Note that our study and that of Marchant and Grant (2015) included different genera in the Leptophlebiidae and Caenidae length-mass relationships (see Fig. 1 caption for details). Our Leptophlebiidae, Caenidae and Centroptilum power models generally match those presented in Marchant and Grant (2015) (Fig. 1). Additionally, the study by Marchant and Grant (2015) was conducted in a temperate region of Australia while our study was conducted in a tropical/subtropical region. Thus, the similarity in the Centroptilum models suggests that regional climate does not appear to influence the length-mass relationship for this taxon, indicating that models from either study could be used to calculate biomass.

The similarity in the length-mass relationships presented in this study and Marchant and Grant (2015) also suggest that the preservation of specimens had little influence on body mass estimates. Our specimens were preserved in formalin for approximately one month, while Marchant and Grant (2015) processed fresh specimens. Thus, this comparison agrees with Benke and Huryn (2007) who suggest that the preservation of specimens in formalin will provide estimates of body mass similar to non-preserved specimens.

While our power equations were generally similar to those presented in Marchant and Grant (2015), comparing the power models of our order/family level relationships with those from Europe, North America and New Zealand showed a much different pattern (Figure 2; see Appendix S1: Table S1 for power model parameters). For Ephemeroptera, the model from previous studies produced similar patterns, while our model produced shallower relationship. In contrast, our model for Chironomidae was similar to all other studies except for Towers et 
al. (1994), which produced a much steeper relationship. While the reason for the heavier Chironomidae in New Zealand is not apparent, Towers et al. (1994) measured a small number of individuals $(\mathrm{n}=23)$ from very small size classes $(2.1-4.1 \mathrm{~mm})$ and large measurement errors can occur when weighing small-bodied individuals (Burgherr \& Meyer 1997; Johnston \& Cunjak 1999; Mährlein et al. 2016). We circumvented this issue by grouping large numbers of Chironomidae during weighing. The models for Trichoptera were variable among studies, with our model being the shallowest and similar to that of Baumgärtner and Rothhaupt (2003). Finally, our Odonata model was much steeper than Benke et al. (1999). There are many reasons for the similarities/ differences in the length-mass relationships among the studies presented in Figure 2, including the genera/species included in each taxonomic group; variation in body shape and size among taxa; and range of size classes included in each length-mass relationship. It is not the intent of this study to determine the drivers of these differences in length-mass relationships but to merely illustrate that there can be relatively large differences in these relationships among the same taxonomic group.

Our results also illustrate the degree to which differences among models can influence biomass estimates. For example, consider the power model for Ephemeroptera presented in Figure 2. If we use the model from each study to calculate biomass for one individual per size class (size class range 1-13 $\mathrm{mm}$ ) and then sum the biomass estimates from each model, we find that total biomass is $40 \mathrm{mg}$ dry mass using Benke et al. (1999) or Towers et al. (1994), 35 mg dry mass using Baumgärtner and Rothhaupt (2003), and 20 mg dry mass using the model from this study. The percent difference among these estimates of biomass ranges from $13 \%$ to $67 \%$, which indicates that the choice of model can potentially have a large influence on biomass estimates.

While the use of length-mass relationships from different studies is a relatively oblivious source of variability in biomass estimates, the use of either a power or linear model 
can also influence biomass calculations. For example, using the power and linear model for Atalophlebia from Table 1 to calculate biomass for one individual per size class (size class range $1-13 \mathrm{~mm}$ ) and then summing the biomass estimate, we find that the percent difference between models is $\sim 15 \%$. In contrast, the percent difference between the power and liner model for Centroptilum is $\sim 3 \%$. Importantly though, the percent difference in biomass estimates is not the same for all size classes. For Atalophlebia, the percent difference between the power and linear model was $\sim 108 \%$ for the $1 \mathrm{~mm}$ size class and $\sim 6 \%$ for the $13 \mathrm{~mm}$ size class. Centroptilum showed a similar pattern with the percent difference in the $1 \mathrm{~mm}$ and 13 mm size classes being $\sim 33 \%$ and $\sim 7 \%$, respectively. These results illustrate that model choice can potentially have a large influence on biomass estimates, as well as other calculations built from biomass estimates, such as massspecific elemental composition and secondary production. Note, however, that the variability within or among length-mass relationships is often much less than the variability in taxon abundance among replicate field samples (Méthot et al. 2012). Thus, when deciding whether to use existing length-mass relationships or developing project-specific relationships, researchers need to assess the various sources of error that can potentially influence the results of a study.

While our study expands the number of reliable length-mass relationships for Australian freshwater macroinvertebrates, significant gaps still exist. Reliable models are not available for Hemiptera and Coleoptera and no models are available for Plecoptera, Lepidoptera, Megaloptera, Mecoptera and Neuroptera. Furthermore, the current data sets cannot adequately assess regional variations in Australian length-mass relationships. Thus, future efforts are required to better document the length-mass relationships of Australian freshwater macroinvertebrates. 


\section{References}

Baumgärtner D. \& Rothhaupt K. O. (2003) Predictive length-dry mass regressions for freshwater invertebrates in a pre-alpine lake littoral. International Review of Hydrobiology: A Journal Covering all Aspects of Limnology and Marine Biology 88, 453-463.

Benke A. C. \& Huryn A. D. (2007) Secondary production of macroinvertebrates. In Hauer F. R. \& Lamberti G. A. (eds), Methods in Stream Ecology, 2nd ed. Academic Press/Elsevier, Burlington: 691-710.

Benke A. C., Huryn A. D., Smock L. A. \& Wallace J. B. (1999) Length-mass relationships for freshwater macroinvertebrates in North America with particular reference to the southeastern United States. Journal of the North American Benthological Society 18, 308-343.

Burgherr P. \& Meyer E. I. (1997) Regression analysis of linear body dimensions vs. dry mass in stream macroinvertebrates. Archiv für Hydrobiologie 139, 101-112.

Edgar G. J. (1990). The influence of plant structure on the species richness, biomass and secondary production of macrofaunal assemblages associated with Western Australian seagrass beds. Journal of experimental marine biology and ecology 137, 215-240.

González J. M., Basaguren A. \& Pozo J. (2002) Size-mass relationships of stream invertebrates in a northern Spain stream. Hydrobiologia 489, 131-137.

Gowing G. \& Recher H. F. (1985) Further comments on length-weight relationships of invertebrates. Australian Journal of Ecology 10, 195.

Hassell K. L., Kefford B. J. \& Nugegoda D. (2006). Sub-lethal and chronic salinity tolerances of three freshwater insects: Cloeon sp. and Centroptilum sp. (Ephemeroptera: Baetidae) and Chironomus sp. (Diptera: Chironomidae). Journal of Experimental Biology 209, 4024-4032. 
Hawking J. H., Smith L. M. \& Le Busque K. (2006) Identification and Ecology of Australian Freshwater Invertebrates. Available at http://www.mdfrc.org.au/bugguide.htm [accessed May - September 2018].

Johnston T. A. \& Cunjak R. A. (1999) Dry mass-length relationships for benthic insects: a review with new data from Catamaran Brook, New Brunswick, Canada. Freshwater Biology 41, 653-674.

Leuven R. S., Brock T. C. \& van Druten H. A. (1985) Effects of preservation on dry-and ashfree dry weight biomass of some common aquatic macro-invertebrates. Hydrobiologia 127, $151-159$.

Mährlein M., Pätzig M., Brauns M. \& Dolman A. M. (2016) Length-mass relationships for lake macroinvertebrates corrected for back-transformation and preservation effects. Hydrobiologia 768, 37-50.

Marchant R. \& Grant T. R. (2015) The productivity of the macroinvertebrate prey of the platypus in the upper Shoalhaven River, New South Wales. Marine and Freshwater Research 66, 1128-1137.

McKie B. G., Cranston P. S. \& Pearson R. G. (2004). Gondwanan mesotherms and cosmopolitan eurytherms: effects of temperature on the development and survival of Australian Chironomidae (Diptera) from tropical and temperate populations. Marine and Freshwater Research 55, 759-768.

Méthot G., Hudon C., Gagnon P., Pinel-Alloul B., Armellin A., \& Poirier A.-M. T. (2012) Macroinvertebrate size-mass relationships: how specific should they be? Freshwater Science 31: $750-764$. 
Pidgeon R. W. J. (1978) Energy flow in a small stream community: an evaluation of the effects of different riparian vegetation. PhD thesis, University of New England, New South Wales.

R Core Team (2020). R: A language and environment for statistical computing. R 3.6.3. Vienna, Austria: R Foundation for Statistical Computing.

Suter P. J., Conrick D., Choy S. \& Cockayne B. (2002) Habitat profiles of Queensland Mayflies, Families Baetidae, Caenidae and Prosopistomtidae. Cooperative Research Centre for Freshwater Ecology: Albury, New South Wales.

Theischinger G. \& Hawking J. H. (2003) Dragonflies of Victoria: an identification guide to adult and larval dragonflies (Odonata). Cooperative Research Centre for Freshwater Ecology: Albury, New South Wales.

Towers D. J., Henderson I. M. \& Veltman C. J. (1994) Predicting dry weight of New Zealand aquatic macroinvertebrates from linear dimensions. New Zealand Journal of Marine and Freshwater Research 28, 159-166.

\section{Author contribution}

Vladimíra Dekanová: Conceptualization (supporting), data curation (lead), formal analysis (lead), investigation (lead), methodology (lead), project administration (supporting), supervision (supporting), visualization (supporting), writing-original draft (lead), writingreview \& editing (supporting)

Michael P. Venarsky: Conceptualization (lead), data curation (supporting), formal analysis (supporting), investigation (supporting), methodology (supporting), project administration (lead), supervision (lead), visualization (lead), writing-original draft (supporting), writingreview \& editing (lead) 
Stuart E. Bunn: Conceptualization (supporting), data curation (supporting), formal analysis (supporting), investigation (supporting), methodology (supporting), project administration (supporting), supervision (supporting), visualization (supporting), writing-original draft (supporting), writing-review \& editing (supporting)

\section{Conflict of interest}

We confirm that we have no conflict of interest to disclose. 
Table 1. Length-mass relationships of freshwater aquatic insects from Cedar Creek (CC) and Yelko Waterhole (YW), Queensland, Australia.

Data were fitted using a power model $\left(\mathrm{DM}=a \mathrm{BL}^{b}\right)$ and a natural log-transformed linear model $(\ln \mathrm{DM}=\ln a+b \ln \mathrm{BL})$. DM is dry body mass (mg) and BL is body length (mm) and $a, b$ are constants.

$a$ and $b$, fitted regression constants; $n$, total number of data points in each model; $R^{2}$, coefficient of determinant; Range, size range of body length included in regression $(\mathrm{mm})$; SE, standard error of the estimate.

Note that we pooled multiple individuals of smaller size classes into a single weighing pan, meaning that $\mathrm{n}$ does not necessarily

represent the total number of individuals for each equation

${ }^{\dagger}$ Number includes individuals identified to genus- and family-level 


\begin{tabular}{|c|c|c|c|c|c|c|c|c|c|}
\hline \multirow[b]{2}{*}{ Taxa } & \multicolumn{3}{|c|}{ Linear model } & \multicolumn{3}{|c|}{ Power model } & \multirow[b]{2}{*}{$n$} & \multirow[b]{2}{*}{ Range (mm) } & \multirow[b]{2}{*}{ Location } \\
\hline & $\ln a \pm \mathrm{SE}$ & $b \pm \mathrm{SE}$ & $\mathrm{R}^{2}$ & $a \pm \mathrm{SE}$ & $b \pm \mathrm{SE}$ & $R^{2}$ & & & \\
\hline Ephemeroptera & $-5.294 \pm 0.103$ & $2.618 \pm 0.066$ & 0.91 & $0.0055 \pm 0.0016$ & $2.653 \pm 0.129$ & 0.78 & $163 \dagger$ & $1.25-12.75$ & $\mathrm{CC}$ \\
\hline \multicolumn{10}{|l|}{ Leptophlebiidae } \\
\hline Atalophlebia & $-5.073 \pm 0.25$ & $2.564 \pm 0.136$ & 0.92 & $0.0210 \pm 0.0196$ & $2.116 \pm 0.393$ & 0.74 & 33 & $1.25-12.75$ & $\mathrm{CC}$ \\
\hline \multicolumn{10}{|l|}{ Caenidae } \\
\hline Irpacaenis & $-5.132 \pm 0.142$ & $2.458 \pm 0.135$ & 0.93 & $0.0008 \pm 0.0003$ & $3.882 \pm 0.220$ & 0.95 & 26 & $1.25-5.75$ & $\mathrm{CC}$ \\
\hline Baetidae & $-5.392 \pm 0.175$ & $2.654 \pm 0.113$ & 0.84 & $0.0128 \pm 0.0036$ & $2.075 \pm 0.151$ & 0.69 & $104 \dagger$ & $1.25-9.5$ & $\mathrm{CC}$ \\
\hline Offadens & $-6.053 \pm 0.214$ & $2.993 \pm 0.14$ & 0.91 & $0.0069 \pm 0.0020$ & $2.378 \pm 0.152$ & 0.84 & 45 & $1.25-9.5$ & $\mathrm{CC}$ \\
\hline Bugona & $-4.765 \pm 0.437$ & $2.392 \pm 0.279$ & 0.66 & $0.025 \pm 0.013$ & $1.769 \pm 0.305$ & 0.52 & 39 & $2.75-7.25$ & $\mathrm{CC}$ \\
\hline Centroptilum & $-5.456 \pm 0.747$ & $2.573 \pm 0.423$ & 0.74 & $0.0060 \pm 0.0066$ & $2.414 \pm 0.580$ & 0.65 & 15 & $3.25-7.75$ & $\mathrm{CC}$ \\
\hline Trichoptera & $-5.857 \pm 0.407$ & $2.549 \pm 0.221$ & 0.76 & $0.0058 \pm 0.0050$ & $2.330 \pm 0.383$ & 0.55 & 45 & $2.25-12.75$ & $\mathrm{CC}$ \\
\hline \multicolumn{10}{|l|}{ Hydropsychidae } \\
\hline Cheumatopsyche & $-6.27 \pm 0.991$ & $2.783 \pm 0.513$ & 0.68 & $0.012 \pm 0.017$ & $2.027 \pm 0.579$ & 0.58 & 16 & $3.75-12.75$ & $\mathrm{CC}$ \\
\hline \multicolumn{10}{|l|}{ Ecnomidae } \\
\hline Ecnomus & $-5.672 \pm 0.418$ & $2.433 \pm 0.233$ & 0.80 & $0.0026 \pm 0.0040$ & $2.678 \pm 0.700$ & 0.49 & 29 & $2.25-10.75$ & $\mathrm{CC}$ \\
\hline Odonata & $-4.218 \pm 0.133$ & $2.721 \pm 0.079$ & 0.89 & $0.014 \pm 0.0033$ & $2.755 \pm 0.083$ & 0.94 & 143 & $2.25-19.75$ & YW \\
\hline Gomphidae & $-5.32 \pm 0.36$ & $3.186 \pm 0.189$ & 0.92 & $0.0025 \pm 0.0018$ & $3.474 \pm 0.264$ & 0.95 & 28 & $2.25-15.25$ & YW \\
\hline Austrogomphus & $-5.949 \pm 0.728$ & $3.393 \pm 0.42$ & 0.89 & $0.0002 \pm 0.0001$ & $4.604 \pm 0.132$ & 0.99 & 10 & $2.25-14.25$ & YW \\
\hline Hemigomphus & $-4.533 \pm 0.261$ & $2.861 \pm 0.131$ & 0.97 & $0.0032 \pm 0.0023$ & $3.370 \pm 0.276$ & 0.96 & 18 & $2.75-15.25$ & YW \\
\hline \multicolumn{10}{|l|}{ Corduliidae } \\
\hline $\begin{array}{l}\text { Procordulia / } \\
\text { Hemicordulia }\end{array}$ & $-4.56 \pm 0.196$ & $3.044 \pm 0.138$ & 0.86 & $0.021 \pm 0.0045$ & $2.682 \pm 0.106$ & 0.89 & 78 & $2.25-9.75$ & YW \\
\hline Libellulidae & $-3.794 \pm 0.274$ & $2.488 \pm 0.136$ & 0.91 & $0.0081 \pm 0.0039$ & $2.940 \pm 0.171$ & 0.95 & 37 & $2.75-19.75$ & YW \\
\hline Urothemis aliena & $-4.404 \pm 0.211$ & $2.728 \pm 0.102$ & 0.97 & $0.0062 \pm 0.0038$ & $3.033 \pm 0.217$ & 0.95 & 28 & $2.75-19.75$ & YW \\
\hline $\begin{array}{l}\text { Hydrobasileus } \\
\text { brevistylus }\end{array}$ & $-2.349 \pm 0.65$ & $1.888 \pm 0.363$ & 0.79 & $0.044 \pm 0.027$ & $2.298 \pm 0.258$ & 0.97 & 9 & $2.75-11.75$ & YW \\
\hline \multicolumn{10}{|l|}{ Diptera } \\
\hline Chironomidae & $-6.311 \pm 0.218$ & $2.435 \pm 0.135$ & 0.90 & $0.0017 \pm 0.0009$ & $2.503 \pm 0.258$ & 0.80 & 38 & $2.25-8.75$ & $\mathrm{CC}$ \\
\hline
\end{tabular}


Chironominae
Orthocladiinae
Tanypodinae

$-6.815 \pm 0.276 \quad 2.739 \pm 0.167$

0.94

$0.002 \pm 0.0016 \quad 2.472 \pm 0.395$

0.82

19

Chironominae
Orthocladiinae
Tanypodinae

$-5.823 \pm 0.404 \quad 2.069 \pm 0.253$

0.92

$0.0008 \pm 0.0005 \quad 2.824 \pm 0.352$

0.96

$0.012 \pm 0.0075$

$1.322 \pm 0.370$

0.66

$11 \quad 3.25-6.75$

$\mathrm{CC}$

$-5.368 \pm 0.493 \quad 1.886 \pm 0.313 \quad 0.80$

$3.25-6.75$

$\mathrm{CC}$ 
Figure 1.

Comparisons of length-mass relationships (power model) from Marchant and Grant (2015) and this study: (a) Leptophlebiidae - Atalophlebia from this study versus Ulmerophlebia, Jappa, Tillyardophlebia, Atalophlebia from Marchant and Grant (2015), (b) Caenidae Irpacaenis from this study versus Tasmanocoenis tillyardi from Marchant and Grant (2015),

(c) Centroptilum - Centroptilum from this study versus Centroptilum elongatum from Marchant and Grant (2015).

See Appendix S1: Table S1 for power model parameters.

Figure 2.

Comparisons of length-mass relationships (power model) for (a) Ephemeroptera, (b)

Odonata, (c) Trichoptera, and (d) Chironomidae among Baumgärtner and Rothhaupt (2003) (Europe), Benke et al. (1999) (North America), Towers et al. (1994) (New Zealand), and this study.

See Appendix S1: Table S1 for power model parameters. 

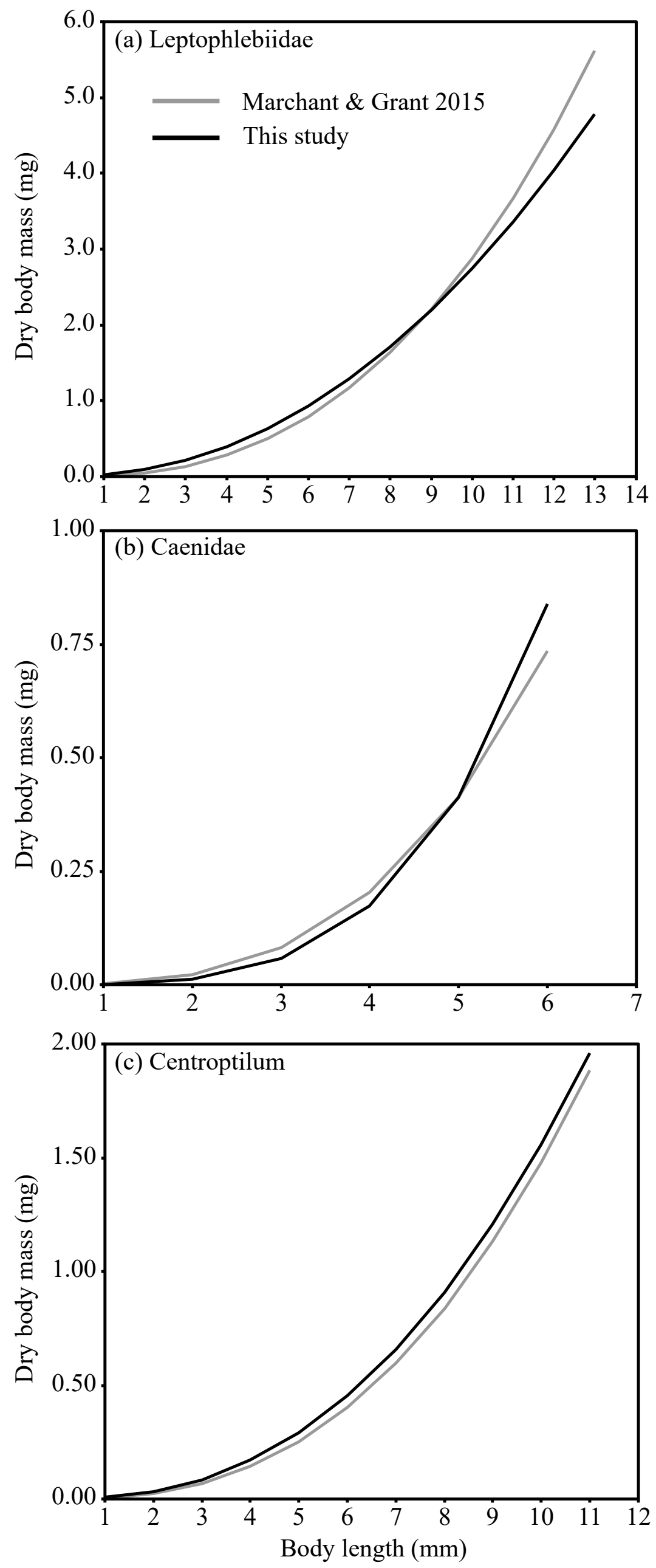

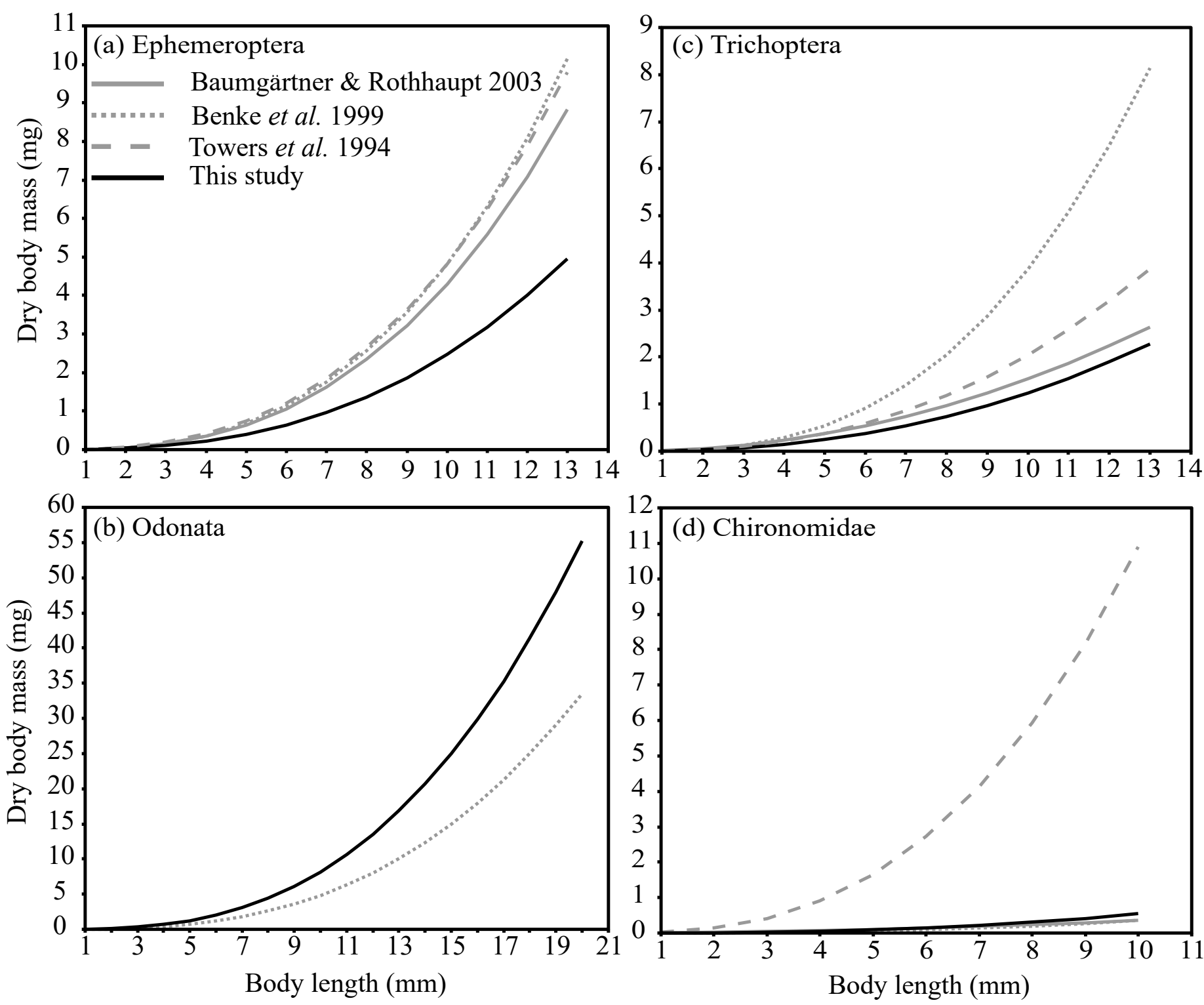
Supplemental material for Dekanová V., Venarsky M.P., Bunn S.E. Length-mass relationship of Australian aquatic invertebrates.

Table S1. Parameters for the power models presented in Figures 1 and 2.

Power model $\left(\mathrm{DM}=a \mathrm{BL}^{b}\right)$, where DM is dry body mass $(\mathrm{mg})$ and $\mathrm{BL}$ is body length $(\mathrm{mm})$ and $a, b$ are constants.

\begin{tabular}{llccc}
\hline & \multicolumn{2}{c}{ Power model } & \\
\hline Figure 1 & $a$ & $b$ & Study \\
& Leptophlebiidae & 0.0083 & 2.54 & Marchant \& Grant 2015 \\
& Caenidae & 0.0025 & 3.17 & Marchant \& Grant 2015 \\
& Centroptilum & 0.0042 & 2.55 & Marchant \& Grant 2015 \\
& Atalophlebia & 0.0210 & 2.12 & This study \\
& Irpacaenis & 0.0008 & 3.88 & This study \\
Centroptilum & 0.0060 & 2.41 & This study \\
Figure 2 & Ephemeroptera & 0.0071 & 2.83 & Benke et al. 1999 \\
& Trichoptera & 0.0056 & 2.84 & Benke et al. 1999 \\
& Chironomidae & 0.0006 & 2.77 & Benke et al. 1999 \\
& Odonata & 0.0078 & 2.79 & Benke et al. 1999 \\
Ephemeroptera & 0.0096 & 2.70 & Towers et al. 1994 \\
Trichoptera & 0.0075 & 2.44 & Towers et al. 1994 \\
Chironomidae & 0.0207 & 2.72 & Towers et al. 1994 \\
Ephemeroptera & 0.0078 & 2.74 & Baumgärtner \& Rothhaupt 2003 \\
Trichoptera & 0.0137 & 2.05 & Baumgärtner \& Rothhaupt 2003 \\
Chironomidae & 0.0057 & 1.80 & Baumgärtner \& Rothhaupt 2003 \\
Ephemeroptera & 0.0055 & 2.65 & This study \\
Trichoptera & 0.0058 & 2.33 & This study \\
Chironomidae & 0.0017 & 2.50 & This study \\
Odonata & 0.0144 & 2.75 & This study \\
\hline
\end{tabular}

